\title{
Investigating the Challenges of the Effective Implementation of E-Learning Courses at Payame Noor University of Dehloran
}

\author{
Rezvan Hakimzadeh, ${ }^{1}$ Marzie Dehghani, ${ }^{1}$ Mohamad Javadipour, ${ }^{1}$ and Ahmad Malekipour ${ }^{2, *}$ \\ ${ }^{1}$ Associate Professor of Curriculum Planning Department, University of Tehran, Tehran, IR Iran \\ ${ }^{2}$ Ph.D. Student in Curriculum Planning, University of Tehran, Tehran, IR Iran \\ "Corresponding author: Ahmad Malekipour, Ph.D. Student in Curriculum Planning, University of Tehran, Tehran, IR Iran, E-mail: malekipour@ut.ac.ir
}

Received 2015 December 01; Revised 2016 June 19; Accepted 2016 June 30.

\begin{abstract}
Introduction: Considering the transformations and developments of the contemporary societies, e-learning education plays a significant role in gaining access to education everywhere, at all time and for everyone. The aim of this study is to investigate the challenges of effective implementation of e-learning courses at Payame Noor University of Dehloran.

Methods: The method used in this research is a descriptive study which employed the survey method. The statistical population comprises 1823 students at PNU of Dehloran in 2014 and 318 (109 males and 209 females) of them were selected as sample by using Morgan and Krejcie table. The tool for collecting data was a researcher-made questionnaire. The validity of the questionnaire was verified by experts and the reliability was found as 0.86 by using Cronbach's Alpha. The data were analyzed via Kolmogorov-Smirnov test, sample T and Binomial proportions using the SPSS software, version 20.

Results: The results illustrated that the behavioral, educational, technical challenges and challenges of human are necessary for effective implementation of e-learning courses in student's view.

Conclusions: In terms of infrastructure, promotion, facilitating and achieving the goals of Payame Noor University, it is necessary that policymakers and planners of Payame Noor University study the current situation, challenges and limitations of e-learning education before implementing e-learning courses. This can make them move toward the vision of PMU.
\end{abstract}

Keywords: Implementation, Effectiveness, E-Learning, Payame Noor University

\section{Introduction}

Reflection on information and communication technology terms is associated with the growing lack of concern and using it in teaching and training human forces will lead to regression in all social, economical, political and cultural fields. Wave of Information and communication technology will affect all aspects of our life and several concepts like electronic business, electronic government, electronic citizenship, electronic banking and electronic health (1). This wave in all fields with different usage and high capabilities which is usable in teaching affairs and imagining teaching without Information technology (more important than the other, computer) seems so difficult (2). Teaching is one of the fields that is hanging due to technological effects such that it increases traditional learning to electronic learning via several internet usage, web and multimedia technology which will transform it to an important teaching instrument in the university (3). Electronic learning phenomenon is a kind of revolutionary technology which presently affects learning in higher education system (4). The objective of this technology is to prepare identical, free availability and search in courses as well as creating similar teaching environment for dif- ferent classes of people in each place and also improving the information technology involved (5). The methods in computer based training (CBT), internet based training (IBT) and web based training (WBT) networks etc. improves teaching and learning contacts in each age without any temporal and local limitations as well as preparing a lifelong learning experience. Therefore, if electronic learning attributed to a collection of teaching activities' that utilize electronic devices like video, audio, computer based, networking, and virtual devices will change the teaching countenance in our country, then, we will understand that transiting from industrial society to information society is not necessarily an advanced movement but a structural ris$\operatorname{ing}(6)$.

Chahill stated that higher education can be faced with these changes and also in field capabilities so that new varieties of work on learning to separation of temporal and local limitations will be possible and will be invested to make compelling perspectives in the future (7). The importance of electronic teaching in the third millennium will create more inevitable attention in research, investment, analysis, and knowing limitations and effective incentives in programming and policies in electronic learning for all governments and nations which is a basic, im- 
portant and inevitable matter. Electronic teaching in Iran is a new industry in teaching and distance education technology; however, institutions and teaching centers especially universities try to give suitable pattern with educational and cultural structure in field of electronic teaching (8). Recently, one of the universities which had vast efforts in field of preparing information and communication technology subsystems is Payame Noor University. Payame Noor University is the biggest higher education center in terms of students and geographical distribution. It is also a trustee of distance learning that tries to ensure that its educational solutions fit the 21th century. It creates an electronic educational system within the educational system in the university to achieve the main objective of the university and also operate higher educational slogan for all people, all the time and all places thereby preparing suitable opportunities for volunteers (9). They deal with learners who are unique, regular in classes than other universities and on the other hand, they are confronted with new strategies of organization based on extending and utilizing more information technology (10). This issue makes it necessary to enhance their skills by maximum usage of students from minimum time during learning (11). Through development and advancing of electronic learning in Payame Noor University, some challenges and limitations led to reduced electronic learning benefits for contacts. Therefore, programmers and politicians of Payame Noor University by preparing more useful platform for effective factors in electronic learning, limitations and challenges will be recognized and will advance by smoothing and fading these limitations. So according to several challenges of electronic learning such as new shapes of virtual learning, fading boarders and leaning limitations, it is necessary that authorities prior to any quick action in this field resolve barriers and challenges that will be encountered. In this study, we refer to several internal and external research levels carried out in some countries. In a study carried out by Farajollahi et al. on checking the usage barriers of Information and communication technology in learning and teaching processes in view of teachers in area 2 of Ghom province, concluded that the barriers of using information and communication technology in learning and teaching process consist of 6 factors, physical subsystems' weakness, management subsystems' weakness, teachers' support weakness, no preparation of teachers' knowledge, no training of teachers for learning in new teaching patterns, no programming of technical lessons and cultural preparations of teachers (12). In a study carried out by Rezaee Rad et al. on checking the role of using electronic learning in the process of teaching and learning in view of faculty members of Payame Noor University of Mazandaran, concluded that the view of Payame
Noor's faculty members plays a significant role in online and present teaching, web network, video conferencing, multimedia, teaching by mobile, television and audio as well as video cassettes (13). In a study conducted by Rahimi et al. on playing electronic learning in medical science and giving solutions, concluded that the most important barriers for electronic learning include no necessary subsystems of technical engineering, no necessary and adequate awareness and lack of experts with no management planning (14). Ribeiro and Moreira concluded that information and communication technology is as an important device for teachers and students for overcoming barriers and increasing skills. Moreover, playing correct teaching from Information and communication technology depends on the awareness of teachers from properties, and learning methods of students in class. Results show that education and training center's teachers should have basic Information technology for supporting the process of teaching and learning (15). In a study carried out by Panda and Mishra on electronic learning in developing large universities: attitude of professors, barriers and encouragement; concluded that from the viewpoint of professors, the most important electronic learning include availability of low speed internet for students and lack of electronic teaching for educational learning, are the most vital electronic learning which restores the interest of people to the use of technology, availability of mental challenges and suitable subsystems for information technology (16). Mungania in a research referred to 7 individual barriers or emotional position, learning methodology, teaching barriers related to organizational barriers, content symmetry, barriers related to technology and different barriers related to technology as barrier of learning. Mungania stated that in a survey via barriers' checking, other barriers like network systems and lack of improvement in environments similar to limited agreement about cooperating is needed in successful learning (17).

As earlier mentioned, it is obvious that with the involvement of Payame Noor University based on its view on the use of information technology in higher education for all people, in everywhere and any time, we should recognize barriers and challenges beside awareness in achieving the goals and objectives of Payame Noor University more than ever before. The objective of this research is to check the available challenges in effective electronic teaching in Payame Noor University of Dehloran. Hence, some questions were asked:

- What are the effective implementations' challenges of electronic teaching periods, behavior challenges?

- What are the effective implementation's challenges of electronic teaching, training challenges?

-What are the effective implementation's challenges of 
electronic teaching, human challenges?

- What are the effective implementation's challenges of electronic teaching, engineering-technical challenges?

\section{Methodology}

This research is an applied research in terms of objective and information collection and also descriptive in terms of survey. Statistical society in this survey comprises all students of Payame Noor University in Dehloran in 2014 which was 1823 persons. Volume of samples obtained by using Mourgan and Krejcie table was 318 people. They were determined by means of categorized sampling method as 109 men and 209 women. In this research, entry parameters in this survey involved students studying for a bachelor degree in first or final year. For information collection in this research, we used questionnaire. Questions in the questionnaire were based on problem's declared and research objectives. Moreover, abstract basis and history of researches were designed. This questionnaire comprises 22 questions collected in 5 point Likert-scale (so muchmuch-sort of-low-so low) with points 0 from 4 . This questionnaire comprises 5 aspects: behavioral challenges (5 items), teaching challenges (7 items), human challenges (4 items) in addition to service and engineering-technical challenges (6 items). Using 10 ideas from experts and specialists in this questionnaire, validity of the questionnaire (Cronbach alpha) was achieved as 0.86 . For data analysis, SPSS software version 20 was employed in statistical aspect, while for description of table, percentage, column diagram, mean and standard deviation and for descriptive statistics, non-parametric test was used. Binomial test is used for testing whether a proportion from a single dichotomous variable is equal to a presumed population value (in this research, 50\% test will be assumed). For this purpose, items 1 to 5 of questionnaire were first divided into two groups:

Group 1: Involved items 1, 2 which denote (very low, low).

Group 2: Involved items 3, 4, 5 which denote (average, high, very high).

In this division, people in group 1 disagreed with challenging the variable, and those in group 2 agreed with challenging the variable at a probability level of 0.05 .

\section{Results}

Frequency distribution of individual features is presented in Table 1 . It shows that female students were the most frequent (209 persons) with 65.1\%, while male students were least frequent (109 persons) about 34.9\% of sample.
Table 1. Frequently Distribution and Percentage of Participant's Gender

\begin{tabular}{l|c|c}
\hline Variable & & Absolute No. (\%) \\
\hline \multirow{4}{*}{ Gender } & Female students & $209(65.1)$ \\
\cline { 2 - 3 } & Male students & $109(34.9)$ \\
\cline { 2 - 3 } & Total number & $318(100)$ \\
\hline
\end{tabular}

Results of proportion tests for checking the first question in Table 2 show respondents see items such as professors' familiarity with modern technologies, students' familiarity with modern technology, students' awareness from available capabilities in site and working with computer as behavioral challenges as a way of effective execution of electronic learning. However, awareness of professors from philosophy of electronic teaching, familiarity of students with other modern technology and their awareness of electronic learning philosophy wasn't assessed as new challenges.

Results of proportions' test for checking the second question in Table 3 shows that respondents see creating an attractive learning environment, high quality electronic content production, execution of rules, and professors' usage of new methods in electronic learning as teaching challenges in the execution of effective electronic teaching, while encouraging active and motivated students, creating environment for encouraging students to carry out individual and group researches and also the necessity of availability of professors and answering the teaching needs of students as challenge in this way, shouldn't be assessed.

Results of proportions' test for checking the third question in Table 4 shows that respondents see full interaction with professor, student to student interaction, correct realizing of virtual teaching benefits, encouraging corporation and team working as teaching challenges in the effective execution of electronic teaching.

Results of proportions for checking the forth question in Table 5 show that respondents see low band's width, no telecommunication subsystems, technical problems, lack of suitable software and hardware, lack of computer new systems and lack of technical and executive support for keeping equipments as teaching challenges in effective execution of electronic teaching.

\section{Discussion and Conclusion}

By developing communication and information technology, electronic teaching is as the most apparent third millennium phenomenon, it has more colorful role in improving higher educations' quality. Currently, electronic 
Table 2. Checking Behavioral Challenge at Probability Level 0.05

\begin{tabular}{|c|c|c|c|c|c|}
\hline Variable's Name & Sample & Categories & Numbers & Observation's Proportion, \% & Meaningful Level \\
\hline \multirow{3}{*}{ Professor's awareness from electronic teaching } & Group 1 & Disagree & 236 & 74 & \multirow{3}{*}{$<0.001$} \\
\hline & Group 2 & Agree & 82 & 26 & \\
\hline & Total number & & 318 & 100 & \\
\hline \multirow{3}{*}{ Professors' familiarity with modern technology } & Group 1 & Disagree & 151 & 47 & \multirow{3}{*}{0.4} \\
\hline & Group 2 & Agree & 167 & 53 & \\
\hline & Total number & & 318 & 100 & \\
\hline \multirow{3}{*}{$\begin{array}{l}\text { Students' awareness of available capabilities in site and } \\
\text { working with computer }\end{array}$} & Group 1 & Disagree & 124 & 39 & \multirow{3}{*}{0.001} \\
\hline & Group 2 & Agree & 194 & 61 & \\
\hline & Total number & & 178 & 100 & \\
\hline \multirow{3}{*}{$\begin{array}{l}\text { Students' familiarity with other available and modern } \\
\text { technologies }\end{array}$} & Group1 & Disagree & 178 & 56 & \multirow{3}{*}{0.38} \\
\hline & Group 2 & Agree & 140 & 44 & \\
\hline & Total number & & 318 & 100 & \\
\hline \multirow{3}{*}{ Students' awareness of electronic learning philosophy } & Group1 & Disagree & 245 & 77 & \multirow{3}{*}{$<0.001$} \\
\hline & Group 2 & Agree & 73 & 23 & \\
\hline & Total number & & 318 & 100 & \\
\hline
\end{tabular}

Table 3. Checking Teaching Challenges at Probability Level of 0.05

\begin{tabular}{|c|c|c|c|c|c|}
\hline Variable's Name & Sample & Categories & Numbers & Observation's Proportion,\% & Meaningful Level \\
\hline \multirow{3}{*}{ Attractive learning environment } & Group 1 & Disagree & 84 & 26 & \multirow{3}{*}{$<0.001$} \\
\hline & Group 2 & Agree & 234 & 74 & \\
\hline & Total number & & 318 & 100 & \\
\hline \multirow{3}{*}{ High quality electronic production } & Group 1 & Disagree & 78 & 25 & \multirow{3}{*}{$<0.001$} \\
\hline & Group 2 & Agree & 240 & 75 & \\
\hline & Total number & & 318 & 100 & \\
\hline \multirow{3}{*}{ Encouraging motivated and active students } & Group 1 & Disagree & 234 & 74 & \multirow{3}{*}{$<0.001$} \\
\hline & Group 2 & Agree & 84 & 26 & \\
\hline & Total number & & 318 & 100 & \\
\hline \multirow{3}{*}{$\begin{array}{l}\text { Creating environment for encouraging students to do } \\
\text { individual and group researches }\end{array}$} & Group 1 & Disagree & 219 & 69 & \multirow{3}{*}{$<0.001$} \\
\hline & Group 2 & Agree & 99 & 31 & \\
\hline & Total number & & 318 & 100 & \\
\hline \multirow{3}{*}{ Execution of rules } & Group 1 & Disagree & 116 & 36 & \multirow{3}{*}{$<0.001$} \\
\hline & Group 2 & Agree & 202 & 64 & \\
\hline & Total number & & 318 & 100 & \\
\hline \multirow{3}{*}{$\begin{array}{l}\text { Professors' usage of new teaching methods in electronic } \\
\text { teaching }\end{array}$} & Group 1 & Disagree & 83 & 26 & \multirow{3}{*}{$<0.001$} \\
\hline & Group 2 & Agree & 235 & 74 & \\
\hline & Total number & & 318 & 100 & \\
\hline \multirow{3}{*}{$\begin{array}{l}\text { Availability of professors and answering to students' teaching } \\
\text { needs }\end{array}$} & Group 1 & Disagree & 166 & 52 & \multirow{3}{*}{0.466} \\
\hline & Group 2 & Agree & 152 & 48 & \\
\hline & Total number & & 318 & 100 & \\
\hline
\end{tabular}

teaching in higher education can serve as a way for teaching several problems in the societies such as the need for more people in teaching, lack of availability to educational centers, lack of economic equipments, lack of experienced teachers and more costs for teaching will be resolved and this issue will require attention to knowledge and challenges and limitations' for resolving the effective execution of electronic teaching. The objective of this study is to test the effective execution of electronic teaching in
Payame Noor University. Hence, this study in relation to behavioral challenges shows that programmers and politicians of Payame Noor University for effective execution of electronic education should attend to factors such as familiarity of professors and students to modern technologies and also awareness of students from available capabilities in site and working with computer. According to this issue, staff of Payame Noor University before executing electronic teaching should ensure that their main con- 
Table 4. Checking Human Challenges at Probability Level of 0.05

\begin{tabular}{|c|c|c|c|c|c|}
\hline Variable's Name & Sample & Categories & Numbers & Observation's Proportion,\% & Meaningful Level \\
\hline \multirow{3}{*}{ Attractive learning environment } & Group 1 & Disagree & 84 & 26 & \multirow{3}{*}{$<0.001$} \\
\hline & Group 2 & Agree & 234 & 74 & \\
\hline & Total number & & 318 & 100 & \\
\hline \multirow{3}{*}{ High quality electronic production } & Group 1 & Disagree & 78 & 25 & \multirow{3}{*}{$<0.001$} \\
\hline & Group 2 & Agree & 240 & 75 & \\
\hline & Total number & & 318 & 100 & \\
\hline \multirow{3}{*}{ Encouraging motivated and active students } & Group 1 & Disagree & 234 & 74 & \multirow{3}{*}{$<0.001$} \\
\hline & Group 2 & Agree & 84 & 26 & \\
\hline & Total number & & 318 & 100 & \\
\hline \multirow{3}{*}{$\begin{array}{l}\text { Creating environment for encouraging students to do } \\
\text { individual and group researches }\end{array}$} & Group 1 & Disagree & 219 & 69 & \multirow{3}{*}{$<0.001$} \\
\hline & Group 2 & Agree & 99 & 31 & \\
\hline & Total number & & 318 & 100 & \\
\hline \multirow{3}{*}{ Execution of rules } & Group 1 & Disagree & 116 & 36 & \multirow{3}{*}{$<0.001$} \\
\hline & Group 2 & Agree & 202 & 64 & \\
\hline & Total number & & 318 & 100 & \\
\hline \multirow{3}{*}{$\begin{array}{l}\text { Professors' usage of new teaching methods in electronic } \\
\text { teaching }\end{array}$} & Group 1 & Disagree & 83 & 26 & \multirow{3}{*}{$<0.001$} \\
\hline & Group 2 & Agree & 235 & 74 & \\
\hline & Total number & & 318 & 100 & \\
\hline \multirow{3}{*}{$\begin{array}{l}\text { Availability of professors and answering to students' teaching } \\
\text { needs }\end{array}$} & Group 1 & Disagree & 166 & 52 & \multirow{3}{*}{0.466} \\
\hline & Group 2 & Agree & 152 & 48 & \\
\hline & Total number & & 318 & 100 & \\
\hline
\end{tabular}

Table 5. Checking Technical- Engineering Challenge in Probability Level 0.05

\begin{tabular}{|c|c|c|c|c|c|}
\hline Variable Name & Sample & Categories & Numbers & Observation Proportion,\% & Meaningful Level \\
\hline \multirow{3}{*}{ Band's width } & Group1 & Disagree & 113 & 36 & \multirow{3}{*}{$<0.001$} \\
\hline & Group 2 & Agree & 205 & 64 & \\
\hline & Total number & & 318 & 100 & \\
\hline \multirow{3}{*}{ Telecommunication's subsystems } & Group 1 & Disagree & 145 & 46 & \multirow{3}{*}{0.084} \\
\hline & Group 2 & Agree & 173 & 54 & \\
\hline & Total number & & 318 & 100 & \\
\hline \multirow{3}{*}{ Technical problems } & Group 1 & Disagree & 130 & 41 & \multirow{3}{*}{$<0.001$} \\
\hline & Group 2 & Agree & 188 & 59 & \\
\hline & Total number & & 318 & 100 & \\
\hline \multirow{3}{*}{ Suitable software and hardware } & Group 1 & Disagree & 144 & 45 & \multirow{3}{*}{0.089} \\
\hline & Group 2 & Agree & 174 & 55 & \\
\hline & Total number & & 318 & 100 & \\
\hline \multirow{3}{*}{ Computer new systems } & Group 1 & Disagree & 117 & 37 & \multirow{3}{*}{$<0.001$} \\
\hline & Group 2 & Agree & 201 & 63 & \\
\hline & Total number & & 318 & 100 & \\
\hline \multirow{3}{*}{ Technical and executive support for keeping equipments } & Group1 & Disagree & 120 & 38 & \multirow{3}{*}{$<0.001$} \\
\hline & Group 2 & Agree & 198 & 62 & \\
\hline & Total number & & 318 & 100 & \\
\hline
\end{tabular}

tacts (professors and students) are fully familiar with job capabilities in reworking and costs and also source positive thoughts of professors and students by means of electronic teaching. In this field, findings of Rahimi et al. Riberio et al. and Mungania $(14,15,17)$ were in line with the results of this study. Other findings of this study in re- lation to teaching challenges, show the necessity of attention in creating an attractive learning environment, producing electronic content, execution of rules and professors' usage of new methods of electronic contents should be given more attention more than ever before. It is obvious that attention to teaching problems in the execu- 
tion of electronic teaching requires frequent efforts; thus, if we don't improve these factors, we wouldn't have results other than surface learning and defeat in students. Mungania (17), referred to similar results. Another finding of this study in relation to human challenges indicates that programmers and politicians in the effective execution of electronic teaching should focus more on human objects such as full interaction with professor, student to student interaction, correct realization of virtual teaching benefits, encouraging corporation and team working. Results of this research in relation to challenges in technical-engineering services indicate that programmers and politicians of Payame Noor should attend to technicalengineering services such as lack of band widths' limitation, lack of telecommunications subsystems, technical problem, lack of software and hardware, old computer systems, lack of technical and executive support for keeping equipments and weakness in preparing electronic teaching sources, these factors require necessary assessment and credits in its survey as electronic learning and its execution. Mungania (17) also resolved that developing electronic learning in big universities: view of professors, barriers and encouragements are equal to research. Results of this study are in line with findings of Farajollahi et al. (12). Rahimi et al. (14) also reported similar findings. Finally, according to research findings and view of Payame Noor University, the use of communication and information technology in higher education for people everywhere and at all time can't be executed without checking virtual teaching subsystems and its objectives. Hence, it is necessary that politicians and programmers of Payame Noor University should check available situations, challenges and electronic teaching limitations before carrying out electronic teaching in Payame Noor University which will be recognized and will advance the way of Payame Noor University.

\section{Footnotes}

Authors' Contribution: Ahmad Malekipour designed, developed the original idea and the protocol, designed training program and analyzed the data in collaboration with Rezvan Hakimzadeh. Mohamad Javadipour and Marzie Dehghani contributed to the editing of the paper.
Conflict of Interest: There is no conflict of interest.

\section{References}

1. Choules AP. The use of elearning in medical education: a review of the current situation. Postgrad Med J. 2007;83(978):212-6. doi: 10.1136/pgmj.2006.054189. [PubMed: 17403945].

2. Kosakowski J. The benefits of information technology 1998. Available from: http://files.Eric.ed.gov/fulltext/ED20302.pdf.

3. Moniee R. Developing of distance education in higher education: challenge \& opportunism. J Rahyaft. 2004;31(1):43.

4. Grison DR, Anderson T. E-Learning in the 21st Century. Tehran: Oloom va Fenoon Publication; 2005.

5. Farhadi R. The workshop Internet Applications in Research 2003. Available from: www.alirezamokhtari.com/arm/internet1.htm.

6. IUI . Transmission and Development Project "- of learning" 2003. Available from: http://www.iranu.com.

7. Chahill R. What motivates faculty participation in e-learning: A case study of complex factors. University of St Thomas; 2008.

8. Zamanpour E, Khani MH, Moradiani DSK. The effect of computer anxiety on attitude towards e-learning: The mediating role of attitude and self-efficacy of computer and internet. QJEduc Psychol. 2013;28(9):7798.

9. Ebrahimzadeh I. Transition from Traditional Distance Learning to Online Learning at PNU: Innovation and Challenge of Change,(A Case Study). QJ Res Plan High Educ. 2007;13(1):113-34.

10. Malekipour A, Malekipour M, Moammerhoor J, Hoseini J, Farzaheh M. Evaluating Computer Literacy among Students of Dehloran Payam-eNoor University. Interdisciplinar J Virt Learn Med Sci. 2014;5(4):45-52.

11. Franz C. Techniques to help e- learning 2004. Available from: http:// ezinearticles.com/?cat=Self-Improvement.

12. Farjollahi M, Moeini KM, Abbasi R. A study of the barriers to applying ict in teaching and learning process from the viewpoints of the qom's 2nd area teachers. J Inf Commun Technol Educ Sci. 2013;3(11):57-70.

13. Rezai Rad M, Mohammadi Atargaleh R. Assessing the Role of Applying E-Learning in the Training and Learning Process from Faculty Members` Point of View at Payam Noor University, Mazandaran. Interdisciplinar JVir Learn Med Sci. 2012;3(3):1-2.

14. Rahimi B, Jebraeily M, Mehdi Oghli R, Rashidi A, Masomi R. The barriers of e-learning implementation in medical sciences domain and provided the necessary solutions. J Urmia Nurs Midwifery Faculty. 2013;11(6):0.

15. Ribeiro JM, Moreira A, Almeida AMP. Preparing special education frontline professionals for a new teaching experience. United States Nat Council Disabil. 2009

16. Panda S, Mishra S. E-Learning in a Mega Open University: Faculty attitude, barriers and motivators. Educ Media Int. 2007;44(4):323-38. doi: $10.1080 / 09523980701680854$.

17. Mungania P. Employees' perceptions of barriers in e-learning: The relationship among barriers, demographics, and e-learning selfefficacy. University of Louisville Louisville KY; 2004. 